\section{... and then there was none?}

SIR-Those who fear for the future of Medical Research Council (MRC) support for science may have had their sensibilities excited by an advertisement for the new post of head of public relations for the council, which appeared in The Times of 28 June 1989.

The appointee was "expected to establish close links with the media, Parliament and with the Council's research scientist" (my italics). The singularity implied in this statement has an ominous ring!

Incidentally, university academics with frustrated professorial ambitions might find PR work for the MRC rather more rewarding financially. In addition to the flexible working hours and generous holidays that they already enjoy, an attractive annual salary of up to $£ 30,000$ (upon proven merit) is on offer.

Biochemistry Department,

Peter B. NunN

King's College London

Strand,

London WC2R 2LS, UK

\section{Ozone layer tax}

SIR-We are all aware that a whole class of chemicals - chlorofluorocarbons (CFCs) - cannot be used freely as they once were because of their destructive effect on the upper-atmospheric ozone layer. And, to make things worse, carbon tetrachloride and methyl chloroform must be added to the list of ozone-depleting chemicals. Even CFCs that are not fully halogenated (HCFCs) are not totally innocuous in this regard.

Given the consequences of continued ozone-layer depletion, one can understand why concerned people want CFCs and related substances banned altogether. I am writing to argue for another, and more flexible, course of action to protect the ozone shield.

I believe every nation should tax ozonedepleting chemicals, heavily if necessary, at the point of manufacture or importation. The more destructive a given compound, the more heavily it should be taxed.

A tax on ozone-depleting chemicals would have the following benefits. First, those who engineer refrigerators and air conditioners would have a powerful incentive to make their designs leak-free. Second, establishments that repair such appliances would have an incentive to recover and recycle CFCs, rather than let them escape. Similarly, industries that use these chemicals for vapour degreasing would be financially motivated to recover, clean up and use them over and over again. Finally, a tax on chlorine- (or bromine-) containing compounds, in proportion to their ozone-depleting power, would motivate engineers to use the least harmful compound feasible in a given application.

The idea behind my proposal is to reduce upper-atmospheric ozone depletion as much as we have to, with the least inconvenience to businesses and consumers alike.

5554 Tamerlane Drive,

ALEXANDER R. KOVNAT

West Bloomfield Township,

Michigan 48322, USA

\section{No lysenkoism}

SIR-Vera Rich (Nature 337, 8; 1989) writes that the changes in the Academy of Sciences in Sofia include the liquidation of lysenkoism in Bulgaria. This is not true. We are not aware of any concrete arguments supporting this conclusion. But it is known that in 1949 there were crude administrative efforts to introduce the theory and personal views of Lysenko in our biological science. Then, in 1956, these administrative efforts were officially discouraged and rejected as unacceptable for the development of science.

Thus Lysenko's influence in Bulgarian scientific investigations was temporary and insignificant. The Bulgarian Academy of Sciences also maintains contacts and encourages scientific collaboration and research with the academies of all the socialist countries and with the leading scientific organizations in France, Italy, West Germany, Spain, Switzerland, Sweden, the United States and other countries, as well as with the Royal Society and the British Academy. These collaborations have resulted in measurable scientific achievements. I am concerned that Vera Rich's article does not contribute to the improvement of positive interactions between scientists, either in the West or East.

IVAN VASSILEV

Central Laboratory of Helminthology,

Bulgarian Academy of Sciences,

Sofia 1113 ,

Bulgaria

\section{Room for theory?}

SIR - V. A. Huszagh and J. P. Infante (Nature 338, 109; 1989) ask whether "the hypothesis in the biological sciences [is] an endangered species". They conclude that it is, notwithstanding the value of (for example) Mitchell's chemi-osmotic hypothesis of oxidative phosphorylation.

The authors point out that "those who review hypotheses in biology are usually data-generators who do not know the elements of importance, and who thus make non-scientific sociologically based objections that are irrelevant to the construction or purpose of a hypothesis", adding that "it took six years after he published them for Mitchell's ideas to be seriously tested by others"

The fact that you published these comments suggests that in principle you agree with them. However, on looking over your Guide to Authors (for example Nature 339, 252; 1989) I find that of the six categories of paper listed, none seems to make room for theoretical work.

"Articles are research reports.... Letters to Nature are short reports of novel findings.... Commentary articles deal with issues in, or arising from, research.... Review Articles survey recent developments in a field..." And News and Views or Scientific Correspondence rule themselves out as likely places for major or even minor theorizing.

I note that, according to Huszagh and Infante, Mitchell's theoretical paper was published in Nature in 1961 (191, 144-148; 1961). In which of the above categories would such a paper fit today?

\section{Jerry Brown Farm,}

C.M. FAIR

\section{Wakefield, Rhode Island 02879, USA}

- Nature does not necessarily agree with the opinions expressed by the authors of Commentary articles. Mitchell's paper was, of course, more than a mere hypothesis; a model of its kind, it begins with a careful marshalling of evidence for the need for a new hypothesis and a demonstration that the chemi-osmotic hypothesis will account for otherwise inexplicable observations. Editor, Nature.

\section{SETI}

SIR-R. A. Michaels (Nature 339, 500; 1989) suggests that extraterrestrial civilizations might send out distress signals if they were aware of an imminent supernova in their vicinity. That seems to be unlikely, as it is probably not possible to predict such an event with sufficient accuracy. There might, however, be other reasons for concentrating the search for extraterrestrial intelligence (SETI) on the vicinity of recent supernovae.

A civilization wishing to signal its presence would do so in a manner that would optimize the chances of detection. That would mean transmitting in the direction opposite in the sky to any recent supernova, as it would be fairly certain that any civilization along that line of sight would be turning its best optical and radio telescopes in the direction of the supernova, if able to do so, just as we did immediately after 1987A.

The two immediate implications are that we should be conducting SETI work in the general direction of 1987A while ourselves transmitting, if we so desire, in the direction of $\omega$ Draconis.

Kapteyn Sterrenwacht,

Nigel DOUgLaS 